\title{
The contribution of Geomatics to increase safety and security in ports
}

\author{
Maurizio Soldani ${ }^{1}$ (D)
}

Received: 14 October 2020 / Accepted: 27 April 2021

(c) The Author(s) 2021

\begin{abstract}
In this paper, the advantages achievable from the use of two prototype systems that are being developed to increase safety and security in ports are shown. Both systems start by monitoring environmental parameters in harbors, and then process data acquired. The first system has been conceived to be helpful to port communities (port authorities, pilots) to optimize harbor waterside management (ship's navigation and cargo, dock performances, boat moorings, refloating of stranded ships, water quality control). By monitoring and processing sea level and atmospheric pressure in port areas, it can help port communities, e.g., to choose the best time when a ship with a certain draft can enter or leave a harbor, or to plan the best route inside the basin for that vessel (port safety). The second system, instead, has been designed for port protection purposes: by monitoring and processing the Earth's magnetic field below the sea surface in harbors (where the natural field is disturbed by a high artificial component), it is able to detect the possible presence of intruders (e.g., divers) swimming underwater in prohibited areas (port security). Here, the results of monitoring and processing activities of the two systems performed in Livorno and La Spezia harbors are shown (Italy). The processing procedures and the graphical interfaces of the systems are based on applications under development by the research team the author belongs to, by using $\mathrm{C \#}$ and $\mathrm{C}++$ languages; Matlab environment has been employed for simulations.
\end{abstract}

Keywords Port navigation safety $\cdot$ Meteorological tides $\cdot$ Port protection $\cdot$ Underwater detection systems

\section{Introduction}

During the last 15 years, a lot of "anomalous" tidal fluctuations (the so-called meteorological tides) have been observed in Italian harbors, due to hydrostatic compensation following perturbations in atmosphere weight. A multi-year statistical analysis carried out in several ports allowed to obtain, port by port, an estimate of the hydro-barometric transfer factor $\mathrm{J}_{\mathrm{ph}}$ that represents the Newtonian correlation between the atmospheric pressure variation $\Delta \mathrm{p}$ and the consequent sea level change $\Delta \mathrm{h}$.

The knowledge of $\mathrm{J}_{\mathrm{ph}}$ is very useful in harbor waterside management (optimization of ship navigation, dock performances, boats mooring, and refloating of stranded ships).

The effects of pressure variations on water depth can be applied to bathymetric maps in harbors: an expected change of atmospheric pressure can be converted, through $\mathrm{J}_{\mathrm{ph}}$, into

Maurizio Soldani

maurizio.soldani@ingv.it

1 Istituto Nazionale di Geofisica e Vulcanologia, Via di Vigna Murata 605, 00143 Roma, Italy a meteorological tide and then, also taking into account the forecasted astronomical tide, into a new bathymetric map. To automate this, a software tool is being developed for dynamic updating bathymetric maps in ports, depending on the sea level measured (coming from mareographic stations in real time or from databases to analyze past events) or on the expected atmospheric pressure (to forecast the future bathymetry). Two threshold levels variable ship by ship, depending on vessel draft, divide the harbor basin into three zones characterized by different colors (green, yellow, and red) that indicate three water depth ranges (respectively deep or allowed for that vessel, shallow or warning, forbidden). By varying the sea level, an area that initially was allowed (green) can become a warning (yellow) or prohibited area (red): this implements what is called a "virtual traffic light" customized for each ship.

After this, the paper shows results obtained during several tests performed to develop a magnetic undersea selfinformed array for peripheral monitoring of port environments for anti-intruders harbor protection: the aim is to detect the presence of underwater threats, such as terrorist divers, in harbors; during the tests, divers performed 
approach runs above the array. The main purpose of the magnetic system is to improve detection performances of sonar systems in the proximity of quays or docks or the seabed (the boundary of water volume to be controlled), or in acoustic shadow zones behind natural or artificial objects; moreover, the magnetic system can work even if it is buried under the sea floor.

Experiments took place in port protection scenarios, characterized by a medium-high environmental magnetic noise that can hide the scuba signal (labile, quasi-point-like and kinetic source). The system has two inputs: the environmental magnetic noise (natural plus artificial) and a signal composed by the same noise superimposed on the target magnetic signal; wavelength of diver signal is inside the noise band; therefore, frequency filtering is inadequate to avoid noise. So, the system uses the noise as filter for the composed signal to extract the target signal and then detect the threat presence; the effectiveness of the procedure is related to the positions of magnetometers: sensors must be so close that they measure the same noise and so far away that only one sensor measures the target signal. To generate alarms when a threat is detected, it is being developed a real-time software application that processes data and turns on a red light and a beep sound when a magnetic anomaly is identified in a certain harbor location.

\section{Geomatics for port safety}

\section{Atmospheric pressure and tides in harbors}

Sea level slow oscillations in harbors are the superposition of several contributions, among which, in Italian ports, the main ones are usually due to the astronomical tides (in particular the diurnal and semidiurnal components).

Unlike astronomical components (periodic and well known), the considerable contribution due to atmospheric pressure changes in harbors (the so-called meteorological tide or "inverted barometer" effect; when atmospheric pressure rises, then sea level falls and vice versa) is currently not foreseeable by means of harmonic analysis (Dobslaw and Thomas 2005; el-Gindy and Eid 1990; Garrett and Majaess 1984; Garrett and Toulany 1982; Le Traon and Gauzelin 1997; Ponte and Gaspar 1999; Tsimplis 1995; Tsimplis and Vlahakis 1994; Wunsch and Stammer 1997).

Meteorological components can in any case lead to significant changes in sea level in port basins: Fig. 1 shows the sea level photographed in the marina of Bocca di Magra (Eastern Liguria, Italy) when there was no astronomical low tide: the wet (and therefore dark) part of the quay wall highlights the decrease in sea level following the rise in atmospheric pressure (good weather conditions).

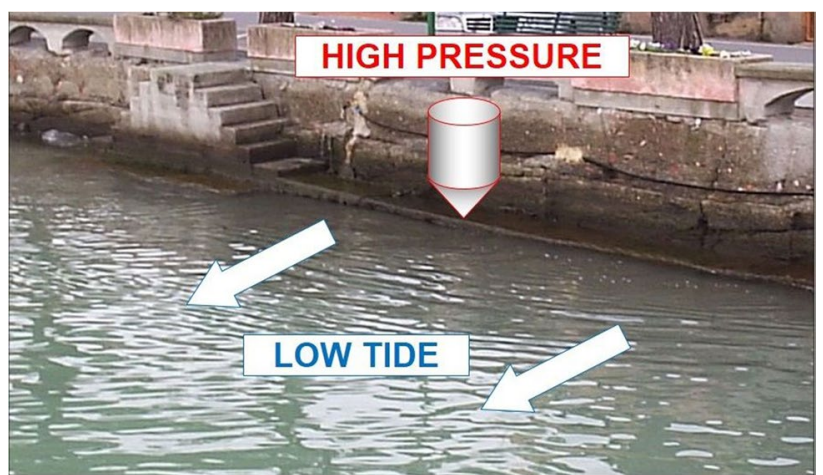

Fig. 1 The evidence of the phenomenon: the decrease in sea level following an increase in atmospheric pressure in marina of Bocca di Magra (Eastern Liguria, Italy)

Moreover, if meteorological tides occur in phase with the astronomical ones, they can induce considerable total variations in sea level in harbors.

In fact, in the last 15 years, a lot of anomalous tidal fluctuations have been observed in Italian ports. ${ }^{1}$

The atmospheric pressure is measured by means of a barometer based on a capacitive silicon transducer: the displacement of the armatures caused by atmospheric pressure variations is converted into an electrical voltage.

The sea level, on the contrary, is acquired by means of a radar transducer positioned above the sea surface: microwave pulses are sent towards the water/air interface; then, knowing the speed of the electromagnetic radiation in the air, the time taken by the impulses on the round trip, and the position of the transducer with respect to IGM's 0 level, the sea level value is calculated.

Then, a multi-year study carried out in several ports allowed us to evaluate the hydro-barometric transfer factor $\mathrm{J}_{\mathrm{ph}}$ from variations of atmospheric pressure (characterized by low-frequency spectral components) to consequent sea level slow fluctuations (Newtonian correlation between atmospheric weight variations and sea level adjustments due to the hydrostatic compensation) (Allen and Denbo 1984; Crépon 1965; Faggioni et al. 2013; Halliwell and Allen 1984; Merriam 1992; Faggioni 2020).

Many occurrences of this phenomenon have been monitored and analyzed.

First of all, only the events during which other possible causes of short-term changes in sea level, such as wind effect or storm surges, were absent have been taken into

\footnotetext{
${ }_{1}$ Data have been acquired by means of meteo-mareographic stations belonging to Italian National Tidegauge Network, managed by ISPRA-Italian Institute for Environmental Protection and Research; data and information about the network can be downloaded from https://www.mareografico.it/.
} 
consideration. Moreover, sea level variations due to longterm phenomena, such as climate change, are not taken into consideration in this study; however, in the next future, a multi-decade statistics of the hydrobarometric transfer factor $\mathrm{J}_{\mathrm{ph}}$ could be used to evaluate, e.g., its possible correlation with global warming.

Then, signals acquired have been subjected to a low-pass filtering that removes higher-frequency oscillations related to astronomical tides and leaves unchanged lower frequencies, related to atmospheric pressure changes.

For each of the events analyzed, the value of the hydrobarometric transfer factor has been calculated as follows:

$J_{p h}=\Delta h / \Delta p$

expressed in absolute value, where:

\section{$\mathrm{J}_{\mathrm{ph}}$ hydro-barometric transfer factor $\left(\mathrm{cm} * \mathrm{hPa}^{-1}\right)$ \\ $\Delta \mathrm{h} \quad$ low-frequency variation of sea level $(\mathrm{cm})$ \\ $\Delta \mathrm{p}$ gradient of atmospheric pressure $(\mathrm{hPa})^{2}$}

By repeating this procedure for all the significant events that occurred in a certain port in a given period (typically one or more years), it was obtained the estimation of the hydrobarometric transfer factor $\mathrm{J}_{\mathrm{ph}}$ for that port during that specific period.

Once known, the hydro-barometric transfer factor allows to estimate a future change in sea level based on the forecasting of atmospheric pressure (it will be sufficient to multiply the expected variation of atmospheric pressure by the $\mathrm{J}_{\mathrm{ph}}$ factor and then reverse the sign, taking into account that pressure and level changes have opposite signs: when one increases, the other decreases).

The $J_{p h}$ factor depends on some elements such as, for example, the conformation of port basin; therefore, it has to be periodically updated, in particular, e.g., after dredging operations.

A statistical analysis carried out on all the events that have occurred in several Italian harbors allowed to obtain, for each port, an estimate of the $\mathrm{J}_{\mathrm{ph}}$ factor. It assumes, in many ports, larger values (even double) compared to the typical $1\left(\mathrm{~cm}^{*} \mathrm{hPa}^{-1}\right)$ of the offshore. In fact, harbors can be considered as semi-constrained basins that as such amplify the phenomenon just described, because the horizontal component of compensation displacement is inhibited towards the coastline (Faggioni et al. 2006).

Two events for which it was calculated the $\mathrm{J}_{\mathrm{ph}}$ factor in Livorno harbor (Italy) are described below. First, Figs. 2 and 3 show, respectively, the atmospheric pressure and the sea level acquired between 3 and 13 September 2010. The date

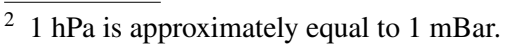

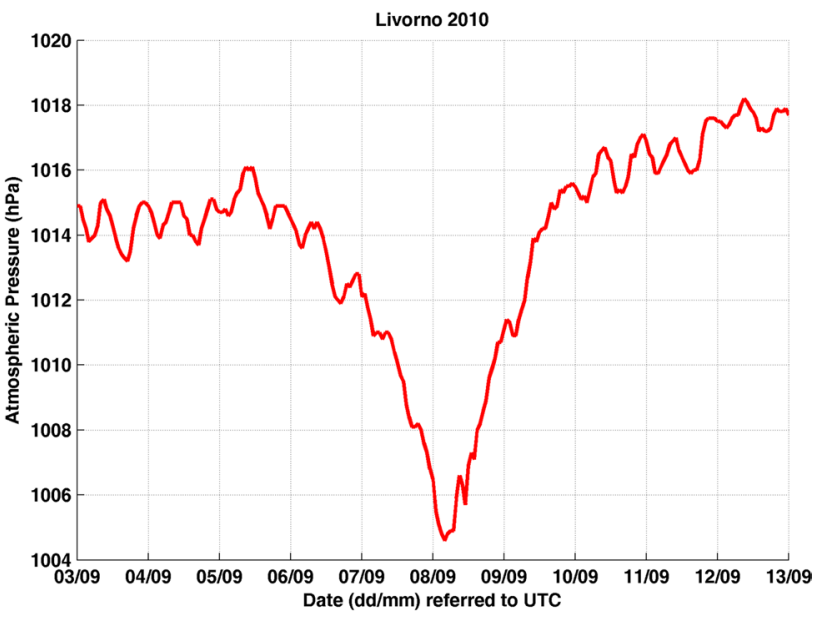

Fig. 2 Atmospheric pressure recorded in Livorno harbor (Italy) between 3 and 13 September 2010

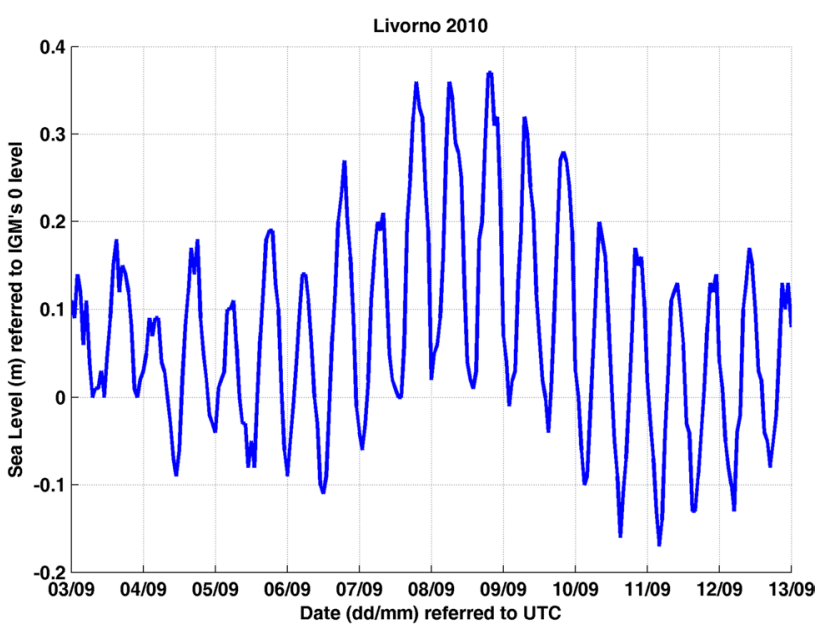

Fig. 3 Sea level recorded in Livorno harbor (Italy) between 3 and 13 September 2010

and the time are referred to Universal Time Coordinates, the sea level to IGM's 0 level (Italian Geographic Military Institute). Figures 4 and 5, on the other hand, show lowfrequency components of signals acquired. Then, Figs. 6, 7,8 , and 9 show the atmospheric pressure and the sea level acquired between 20 August and 1 September 2015, and their low-frequency components.g

In the example shown in Figs. from 2 to 5, a decrease of nearly $8.5(\mathrm{hPa})$ in low-frequency atmospheric pressure $(\Delta \mathrm{p})$ induces an increase of nearly $17.7(\mathrm{~cm})$ in low-frequency sea level ( $\Delta \mathrm{h}$, high meteorological tide). After this, a pressure increase $(\Delta \mathrm{p})$ of about $11(\mathrm{hPa})$ induces a sea level decrease ( $\Delta \mathrm{h}$, low meteorological tide) of about 20.7 [cm]. Then, by calculating the hydrobarometric transfer factor $\mathrm{J}_{\mathrm{ph}}$ as the ratio of $\Delta \mathrm{h}$ and $\Delta \mathrm{p}$, we obtain a value next to $2\left(\mathrm{~cm}^{*} \mathrm{hPa}^{-1}\right)$. 


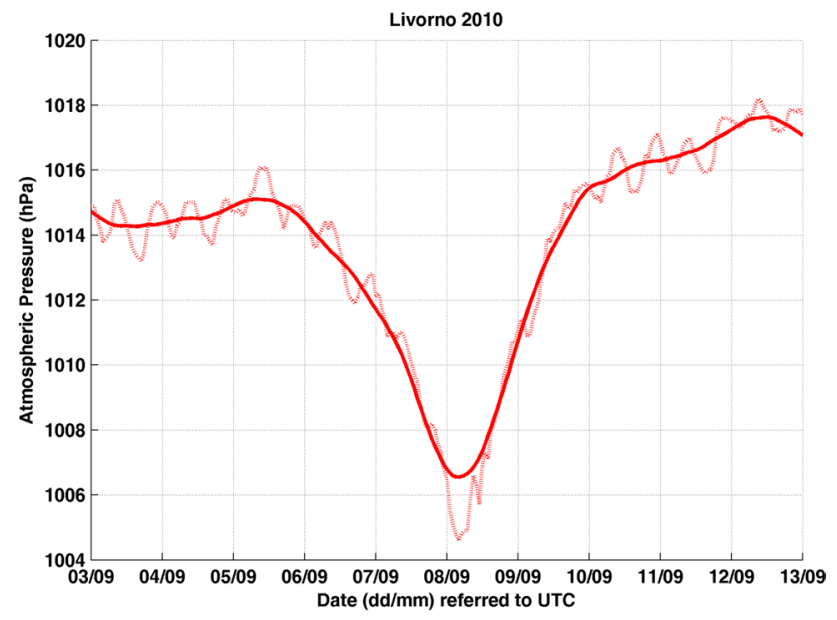

Fig. 4 Low-frequency components of atmospheric pressure in Livorno harbor (Italy) between 3 and 13 September 2010

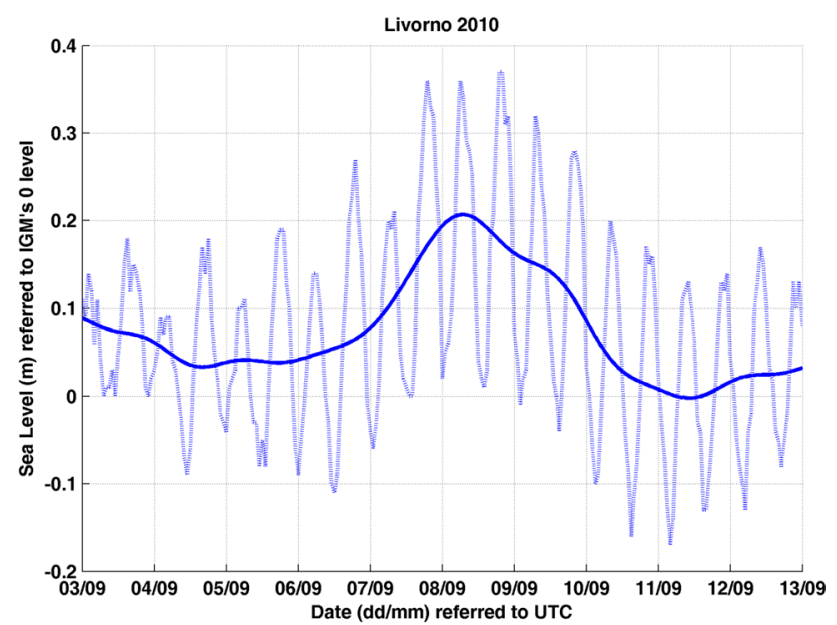

Fig. 5 Low-frequency components of sea level in Livorno harbor (Italy) between 3 and 13 September 2010

In Figs. from 6 to 9, instead, a fall of about $8.7(\mathrm{hPa})$ in low-frequency atmospheric pressure $(\Delta \mathrm{p})$ causes a rise of about $13.8(\mathrm{~cm})$ in low-frequency sea level $(\Delta \mathrm{h})$. After this, a pressure rise $(\Delta \mathrm{p})$ of nearly $10.5(\mathrm{hPa})$ induces a sea level fall $(\Delta \mathrm{h})$ of nearly $18.9(\mathrm{~cm})$. By calculating Jph by means of the described method, we obtain a value of approximately $1.7\left(\mathrm{~cm} * \mathrm{hPa}^{-1}\right)$.

\section{The goal of the research}

The knowledge of $\mathrm{J}_{\mathrm{ph}}$ factor (in addition, of course, to astronomical tide components) is very useful in the harbor waterside management (optimization of ship's navigation and cargo, dock performances, boat moorings, refloating

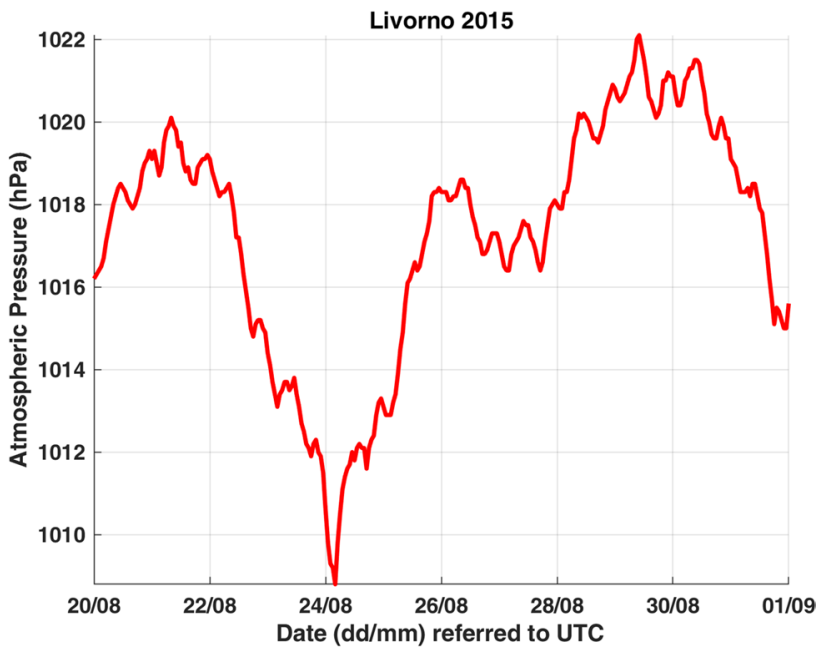

Fig. 6 Atmospheric pressure recorded in Livorno harbor (Italy) between 20 August and 01 September 2015

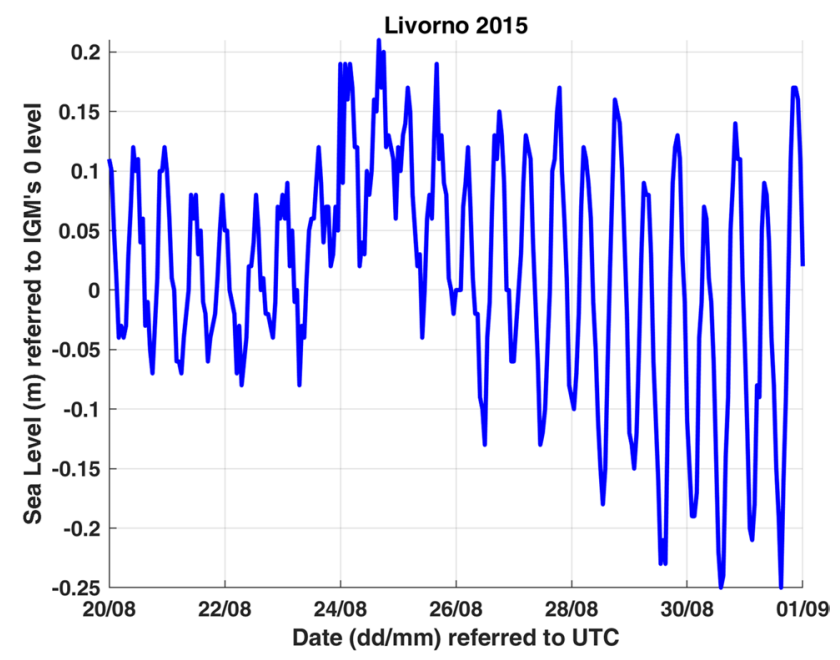

Fig. 7 Sea level recorded in Livorno harbor (Italy) between 20 August and 01 September 2015

of stranded ships, water quality control, ...) to forecast the sea level and then the water depth. Sea level goes down with an atmospheric pressure increase (good weather), and goes up with a pressure decrease (bad weather); then, pressure variations change the bathymetry of a basin. In addition to this, astronomical tide components must be added to (or subtracted from) the meteorological contribution. Obviously, a low tide within a port hinders navigation; vice versa, a high tide facilitates navigation.

So, the effects of tides on water depth can be applied to bathymetric maps in harbors: starting from the bathymetric map of a port, sea level variation generates an updated bathymetric map, a useful tool available to port communities. 


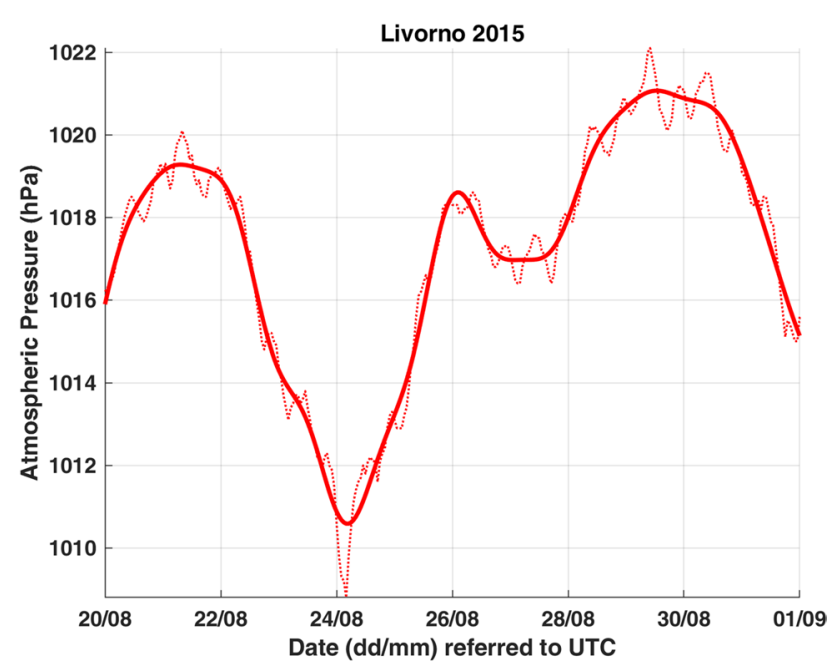

Fig. 8 Low-frequency components of atmospheric pressure in Livorno harbor (Italy) between 20 August and 01 September 2015

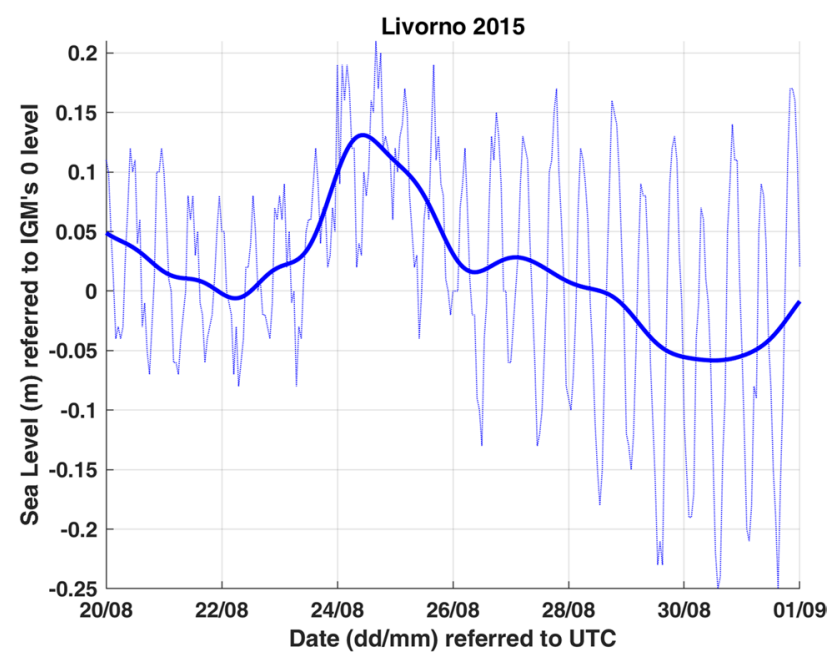

Fig. 9 Low-frequency components of sea level in Livorno harbor (Italy) between 20 August and 01 September 2015

\section{The user interface}

To automate this, a software program is being developed for dynamic updating georeferenced bathymetric maps in harbors (here is shown the case study of the port of Livorno, Italy), depending on the sea level measured in real time by means of mareographic stations (or read from files if the analysis is referred to past events), or on the expected astronomical tides and atmospheric pressure (converted into meteorological tide by means of $\mathrm{J}_{\mathrm{ph}}$ ). This is being done to provide a useful tool to the port community.

Two threshold levels variable ship by ship, depending on vessel draft, divide the bathymetric map of the harbor basin into three zones characterized by different colors (green, yellow, and red); these colors indicate three water depth ranges (respectively deep or allowed for that vessel, shallow or warning, forbidden).

For example, as shown in Fig. 10, for a ship with a draft of $6(\mathrm{~m})$, we could consider as prohibited (red) the areas with depth less than $6(\mathrm{~m})$, warning areas (yellow) those in which the depth is between 6 and $8(\mathrm{~m})$, and allowed areas (green) those where the depth is greater than $8(\mathrm{~m})$; so, thresholds could be set at 6 and $8(\mathrm{~m})$, respectively (the lower threshold is usually chosen equal to the vessel draft, whereas the yellow zone represents a gradual transition from the green area to the red one); in any case, in a hypothetical operational scenario, the choice of thresholds would be a task of end users (port communities).

Instead, for another vessel with a draft equal to $9(\mathrm{~m})$, the thresholds could be set respectively at 9 and $12(\mathrm{~m})$; in this way, the areas with a depth of less than $9(\mathrm{~m})$ are considered prohibited, warning areas those with a depth between 9 and $12(\mathrm{~m})$, and allowed areas those with a depth greater than 12 (m), as shown in Fig. 11.

This implements the so-called virtual traffic light customized for each ship: as the comparison between the two figures shows, the division into allowed, warning, and prohibited areas changes from ship to ship based on its draft: obviously, a ship with a deeper draft will be able to move within a smaller allowed (green) area.

This represents the so-called static analysis. After this, sea level data can be used from the software to update the bathymetry (dynamic analysis) and, consequently, to refresh the division of the map into green, yellow, and red zones based on the same threshold levels (for the same ship, they remain constant at 9 and 12 [m]). Sea level can be read from past measurements stored in files or come in real time from a mareographic station; for future events, sea level can be forecasted starting from astronomical and meteorological tides expected. Therefore, by varying the sea level, an area that initially was prohibited (red) can become a warning (yellow) or allowed area (green) for that vessel.

For example, in the dynamic bathymetric maps shown in Figs. 12 and 13 (thresholds 9 and 12 [m]), the same point (UTM coordinates, Easting 604,515 [m], Northing $4,822,760[\mathrm{~m}]$, indicated by the white arrow) changes from yellow to green light. In fact, its depth increases from 11.60 to $12.29(\mathrm{~m})$, due to sea level rise from 09/12/2017 20:10.00 UTC $(-0.27[\mathrm{~m}])$ to $11 / 12 / 201716: 30.00 \mathrm{UTC}(0.42[\mathrm{~m}])$; more generally, the "green channel" pointed by the arrow becomes wider.

In Figs. 12 and 13, at the bottom right, the date and the time are shown (referred to UTC) relating to the current sea level value (referred to IGM's 0 level) used to update the map; moreover, the UTM coordinates and the depth of the position pointed by the arrow are indicated. The color of the traffic light indicates the current state of that point: red, 


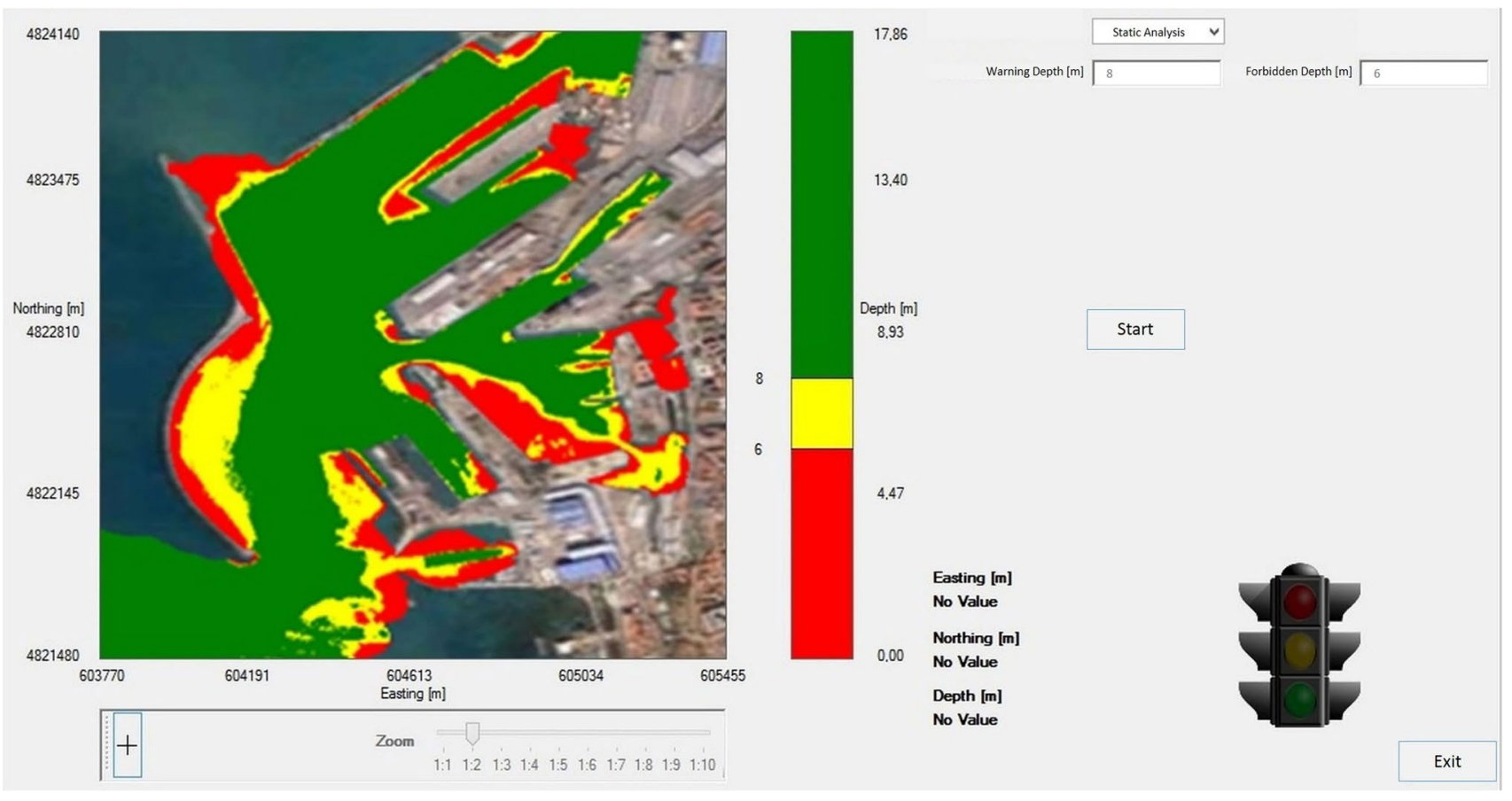

Fig. 10 Virtual traffic lights in the port of Livorno, Italy (thresholds 6 and 8 [m], respectively)
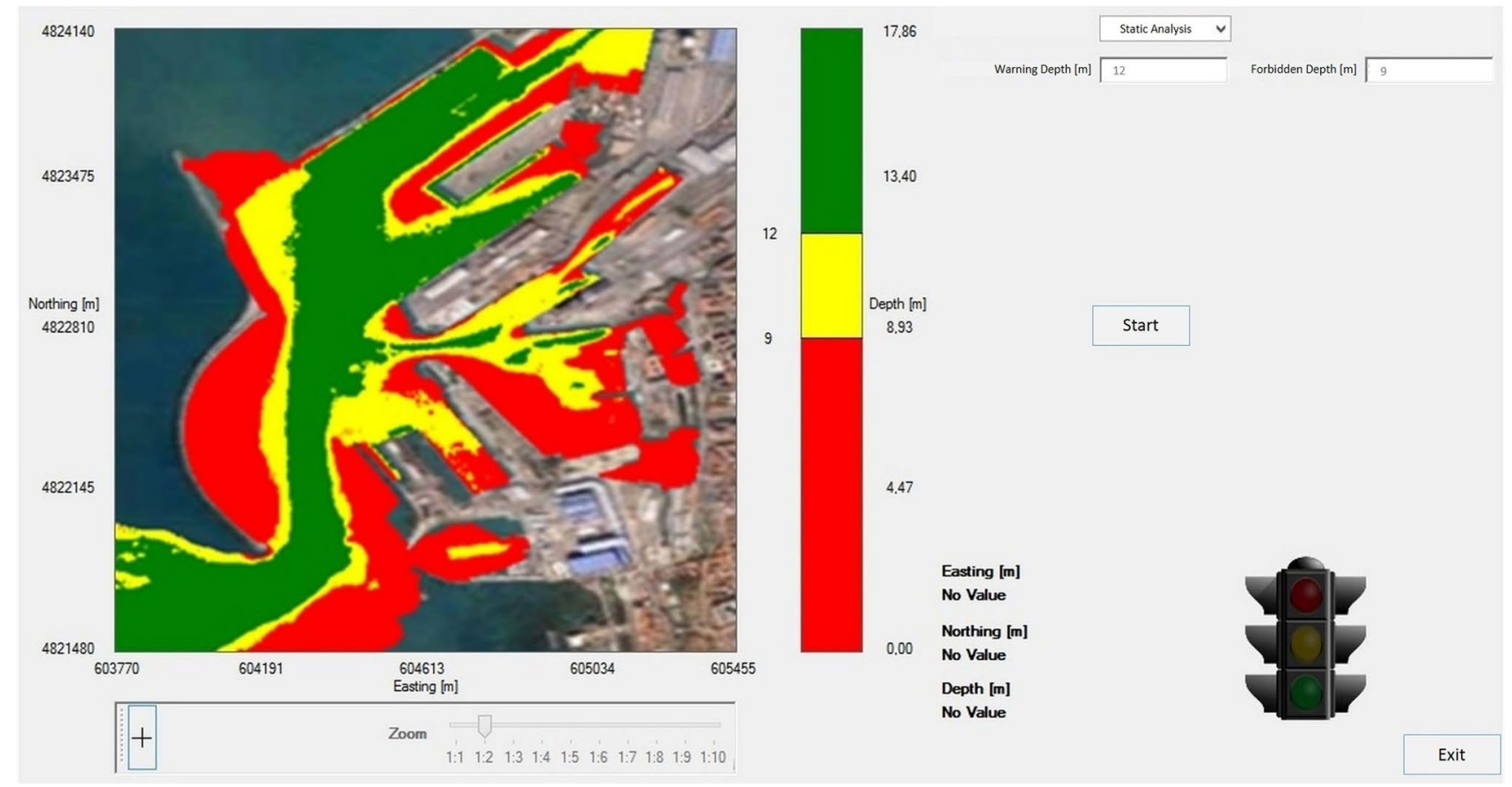

Fig. 11 Virtual traffic lights in the port of Livorno, Italy (thresholds 9 and 12 [m], respectively)

yellow, or green means, respectively, that the position is forbidden, warned, or allowed for that ship at that moment; as the depth of that point is updated with new sea level values, its traffic light can change state and color (yellow in Fig. 12, green in Fig. 13).
The use of virtual traffic lights is obviously reliable insofar as the inputs used are reliable that is in the hypothesis that the starting bathymetric map is still valid (otherwise, it must be updated by performing new surveys) and that the sea level measured by a mareographic station at a certain 


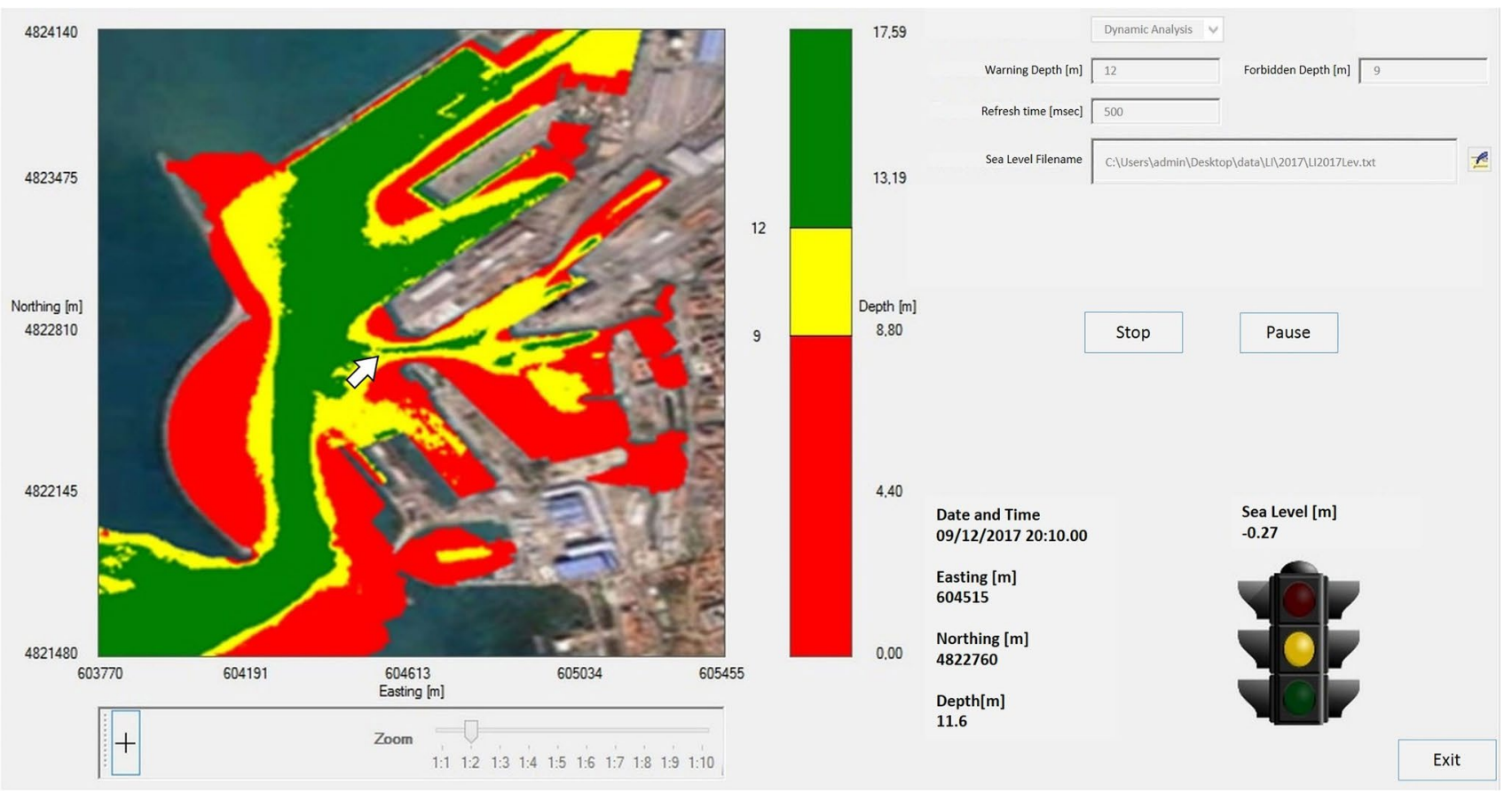

Fig. 12 Virtual traffic lights in the port of Livorno, Italy (thresholds 9 and 12 [m], respectively) on 09/12/2017 at 20:10.00 UTC

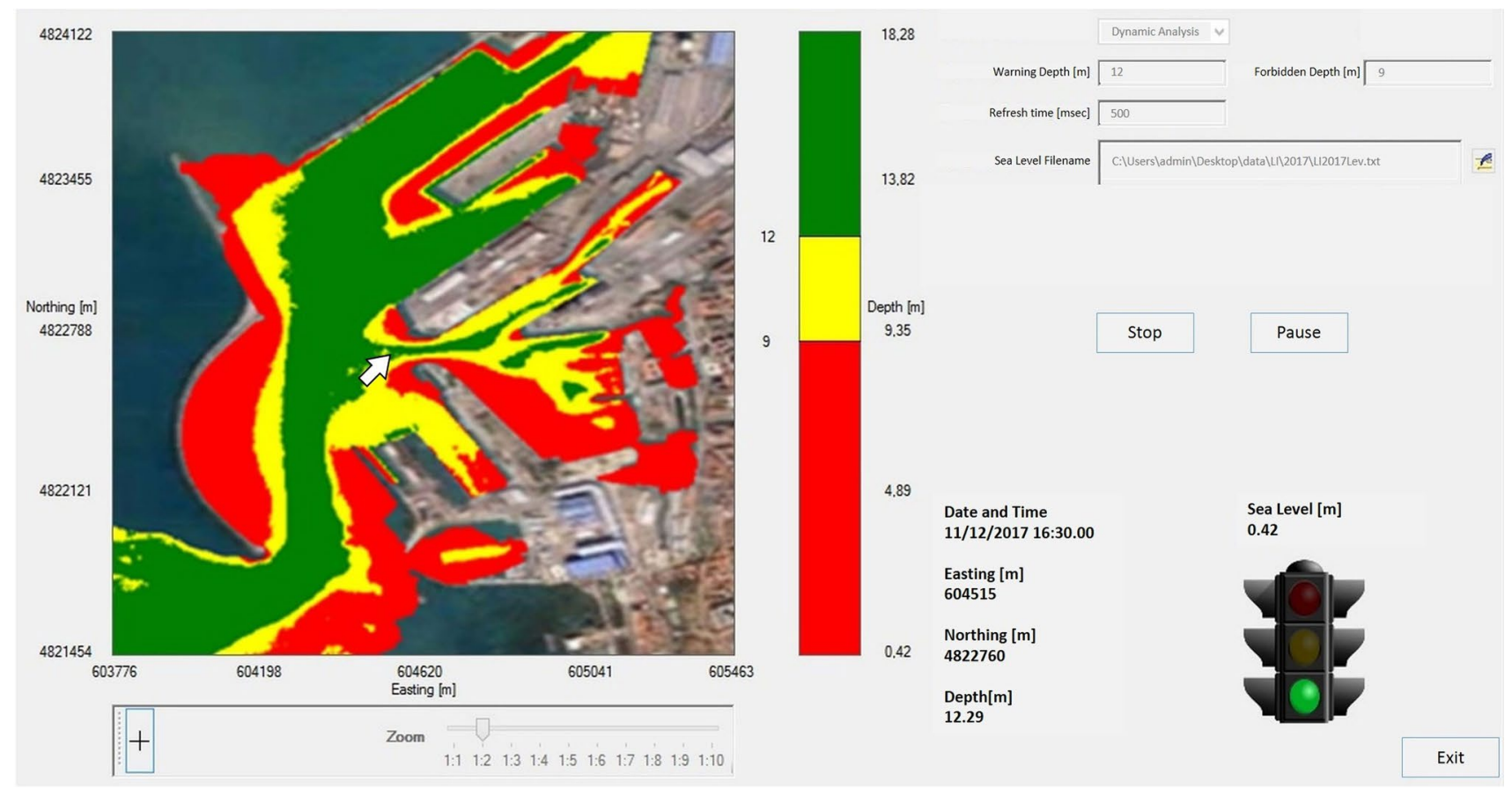

Fig. 13 Virtual traffic lights in the port of Livorno, Italy (thresholds 9 and 12 [m], respectively) on 11/12/2017 at 16:30.00 UTC

position in the basin is representative of the whole port; in any case, the use of a greater number of mareographic stations could allow a better accuracy in the dynamic updating of the map, by using a different sea level value for each basin into which the harbor is divided.
Virtual traffic lights can allow port operators to choose in real time the best route for a specific ship within a port, e.g., to reach a dock or a pier. By using, instead of real time sea level measurements, the expected astronomical tide and atmospheric pressure (converted into sea level forecasting 
by means of the hydrobarometric transfer factor $\mathrm{J}_{\mathrm{ph}}$ ), the map allows to determine the best route in advance, depending on the accuracy of meteorological forecasting; virtual traffic lights can also help to decide the best time when a vessel can enter or leave a port; furthermore, provided that we are able to forecast well in advance the bathymetry of the destination port, they can also be useful in deciding how much a ship can be loaded in its departure port.

\section{Geomatics for port security}

\section{The scenario}

After the terrorist events that characterized the beginning of 2000s, a technological research topic was born with the purpose of developing systems aimed at protecting the socalled critical infrastructures that are those considered most at risk of attacks (industrial plants, military bases, merchant ports, airports, etc.). Research centers, institutions, armies, navies, and industries from all over the world are involved in this area of study.

In particular, in maritime areas, a line of research named port (or harbor) protection arose, to develop systems able to detect the possible presence of threats in harbors and coastal areas. The systems traditionally employed for this purpose in underwater environments make use of sonar systems, which however lose their effectiveness when they have to operate near the seabed or the docks, due to the reflections and attenuations undergone by acoustic impulses emitted.

Here is shown a new anti-intrusion underwater system based on a magnetometer self-informed network that has been developed in the last 15 years, together with the results obtained during several operative tests performed; the goal of the trials was to detect the presence of underwater intruders, such as terrorist divers, swimming underwater in harbors (Faggioni et al. 2009).

This system, consisting of an array of triaxial magnetometers (passive sensors measuring the Earth's magnetic field, without emitting any signal: their operating principle is based on the Faraday's law of electromagnetic induction), is complementary to sonar systems because it better works where the performance of acoustic systems decay, and vice versa.

The main purpose of the magnetic system is therefore to fill the gaps of classical sonar systems, whose performances deteriorate, due to reflections and attenuations, in the boundary of the volume of water to be controlled (sea bed, docks, quays, ...).

The magnetic system is usually deployed on the seabed (typical work depth nearly $10 \mathrm{~m}$ ) and is able to identify, for example, the presence of a scuba swimming near the sensors, distinguishing the signal generated by the diver's

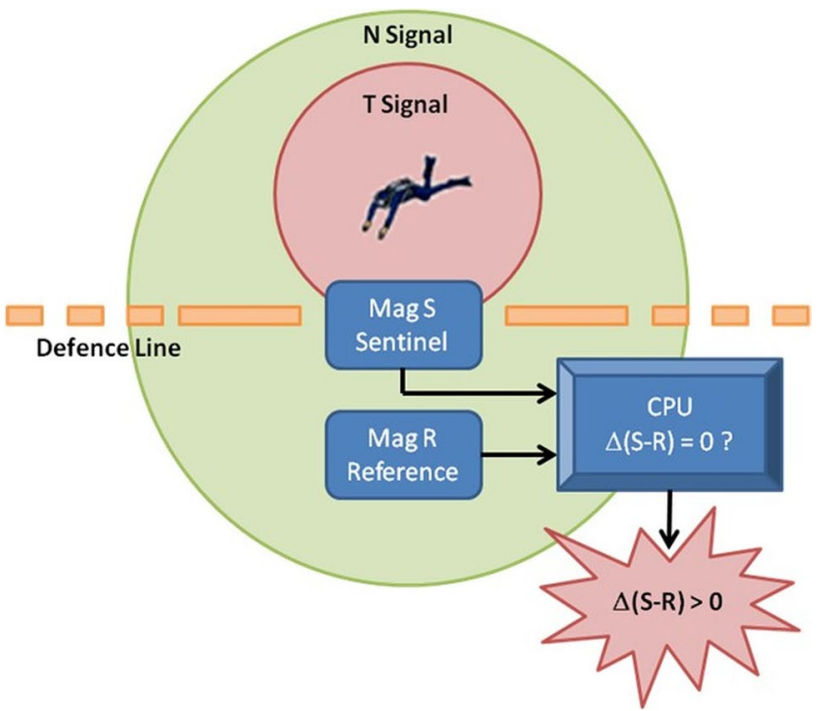

Fig. 14 Schematization of diver's signature overlapped to the background field (picture from Leoncini et al. 2010)

equipment ("anomaly") from the environmental magnetic noise ("background") (Faggioni et al. 2018).

\section{The magnetometer array}

The experiments took place in port environments, characterized by medium-high environmental noise with a relevant human origin magnetic noise component. Divers performed approach runs above the magnetic underwater array.

Divers are labile, quasi-point-like, and kinetic sources: therefore, a processing technique has been developed based on a differential approach to detect labile signals in a highnoise environment. In fact, filtering techniques such as those based on the Fourier transform are inadequate because the frequencies of scuba signals (singularities) are inside the noise band, and signal amplitudes are comparable with the noise ones.

Then, the system has two different input signals: the magnetic background field (natural plus artificial) and a signal composed by the same magnetic background field superimposed on the target magnetic signature. The background noise (characterized by low spatial frequencies) can be schematized by a big area that extends over all the sensors, while the diver's signal (higher spatial frequencies) can be thought as a smallest sphere that affects only one sensor at a time, overlapping the noise area. In Fig. 14, the green area (noise signal) represents the magnetic background field over the whole magnetic system, while the red sphere centered around the scuba (Target signal) depicts its magnetic signature superimposed on the same background field. In this example, only two adjacent magnetometers are represented, we can call one reference and the other sentinel: the 


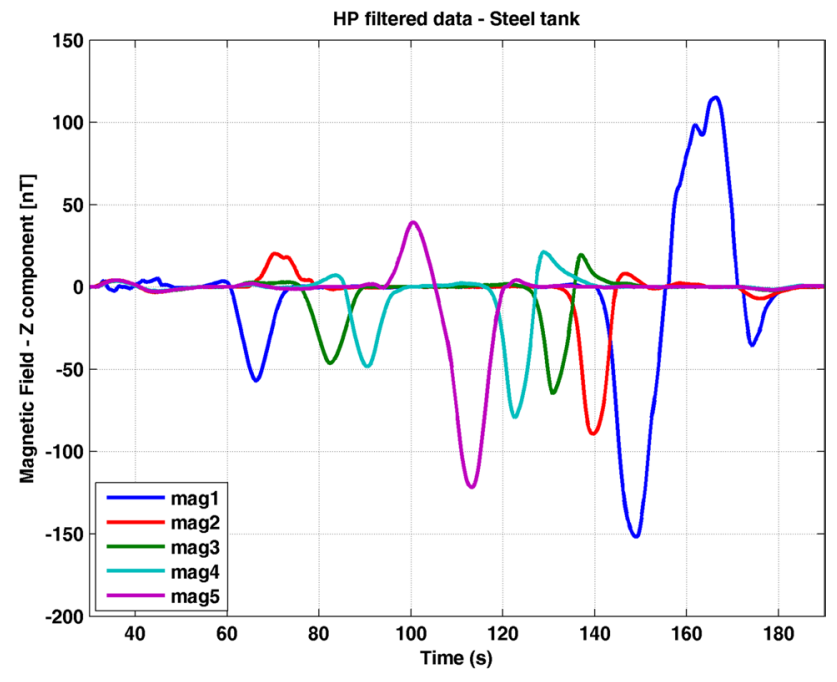

Fig. 15 Signals generated by a diver equipped with a steel tank (after a filtering that eliminates DC component)

reference is the one that records only the background field, while the sentinel records the target signature overlapped to the background field.

Therefore, the system uses the noise signal (background field) as filter for the target signal (background field plus the target signature) to detect the target presence by means of a differential technique (Faggioni et al. 2010): if the difference between the sentinel and the reference acquisitions exceeds a certain threshold, an anomaly is detected and an alarm is generated.

Generalizing the concept described to the whole system, the processing procedure calculates the differences of each sensor with its two neighbors (the preceding and the following along the linear array).

The effectiveness of the procedure is related to the position of magnetic field observation points (reference devices and sentinel device): sensors must obtain correlation in the noise observations (all the sensors record the same background field, in accordance with the so-called space stability or spatial coherence of the magnetic noise) and de-correlations in the target signal observations (only one sensor records the target signature) (Bartels et al. 1992; Cafarella et al. 1992; Chapman 1918; Georgieva et al. 2013; Meloni et al. 2007). The distance between two adjacent sensors is determined based on magnetic characteristics of the weakest magnetic source (the weaker the source, the smaller its sphere) that the system must be able to detect, in this case a diver equipped with an aluminum tank, whose magnetic signature is shown in the following.

Several operational tests were carried out in the Gulf of La Spezia (Italy). The trials have involved the deployment of five magnetometers. Figure 15 shows the signals generated by a diver equipped with a steel tank (well detectable

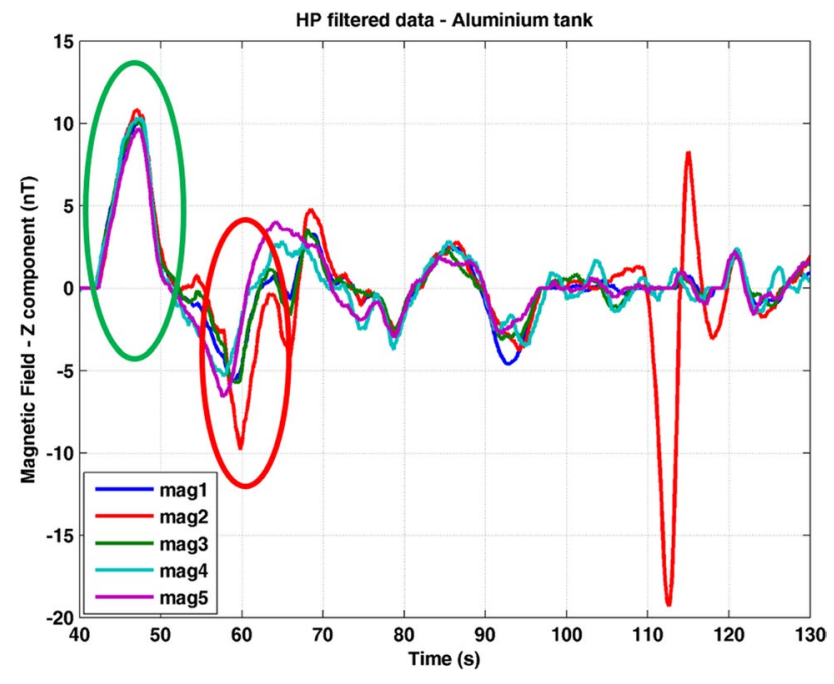

Fig. 16 Signals generated by a diver equipped with an aluminum tank (after a filtering that eliminates DC component)

by magnetic sensors). The passage of the scuba has been detected by each magnetometer while the diver was swimming forth and back along the array.

The $\mathrm{Z}$ component is perpendicular to the seabed and directed towards the center of the Earth. The duration and the amplitude of each pulse depend on the speed of the diver and on its distance from the array (swimming depth is not constant). The different shapes of the pulses (positive, negative, dipole) depend on how the diver approaches the magnetometer axes.

The system has proved able also to detect the presence of much weaker magnetic sources, as in the case shown in Fig. 16, where the diver has been equipped with an aluminum tank.

In this case, the five pulses in the green oval have been classified as background noise because all five magnetometers have been "disturbed" in the same way (no alarm). On the contrary, the red pulse in the red oval has been detected and signaled as an alarm because it has been measured by a single magnetometer and therefore was considered different from the background noise (anomaly), as the bigger one at the end of the sequence.

\section{The user interface}

To generate alarms when a target is detected, a software program has been developed that processes in real-time data acquired by all the magnetometers and turns on a red light and a beep sound when a magnetic anomaly is identified; sensors not alarmed remain green and silent. The user interface is shown in Fig. 17.

Each signal acquired by the sensors is compared with those recorded by all the other magnetometers, to remove 


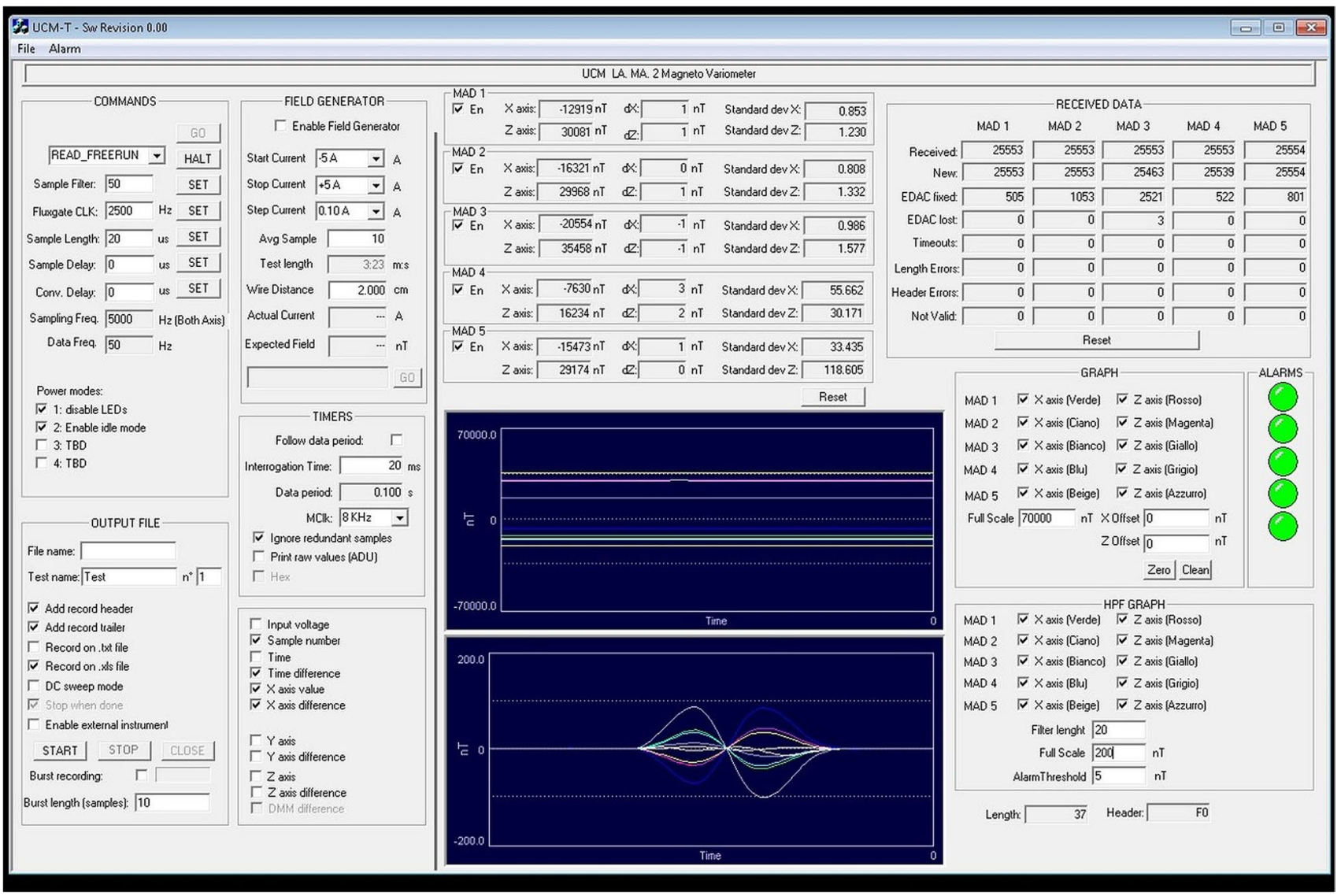

Fig. 17 User interface of the software for signal processing

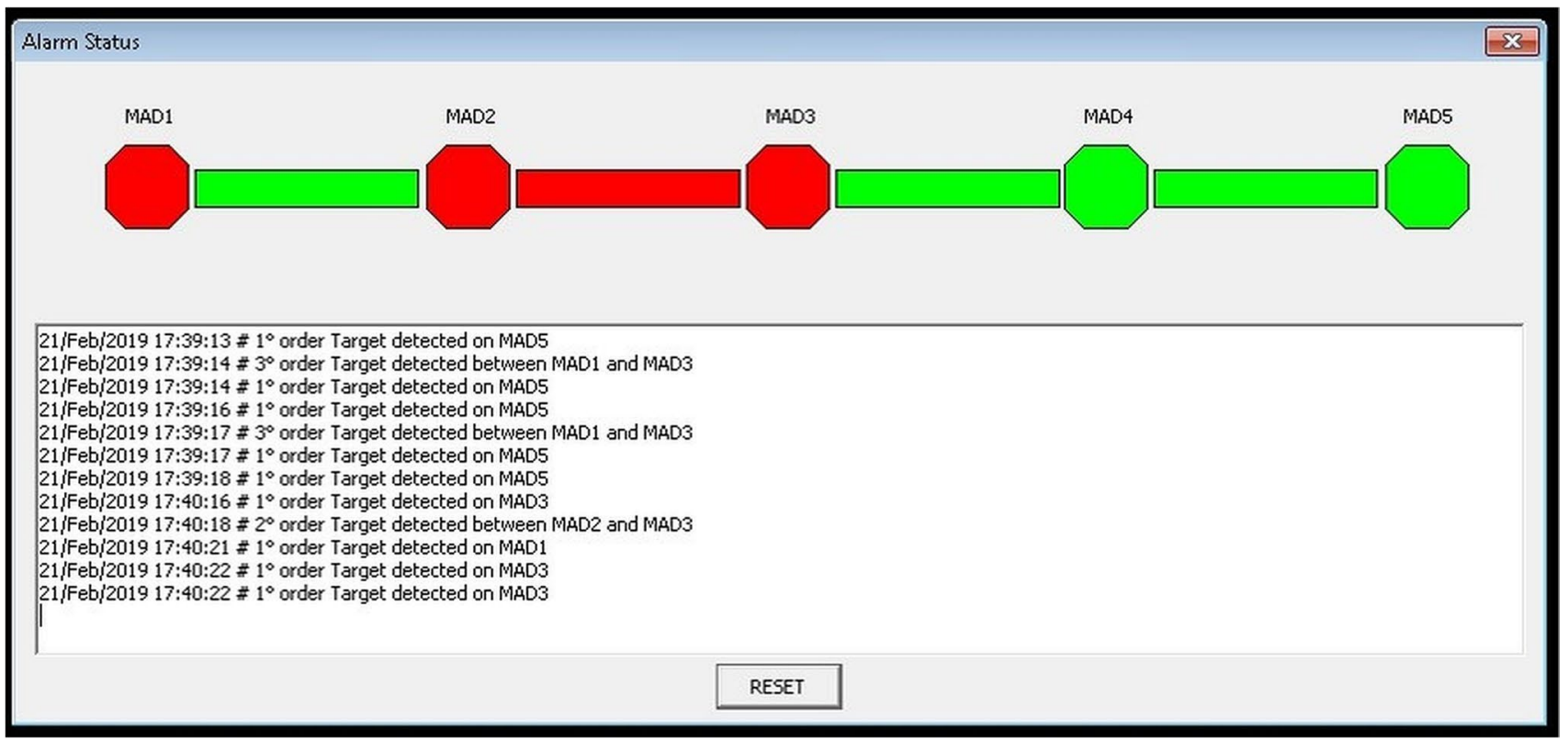

Fig. 18 Detail of the window for alarm generation: alarms generated by a diver passage 
Fig. 19 GNSS/GPS track of the diver and array of magnetometers (red, sensors alarmed; green, sensors not alarmed; picture modified from Google Earth)

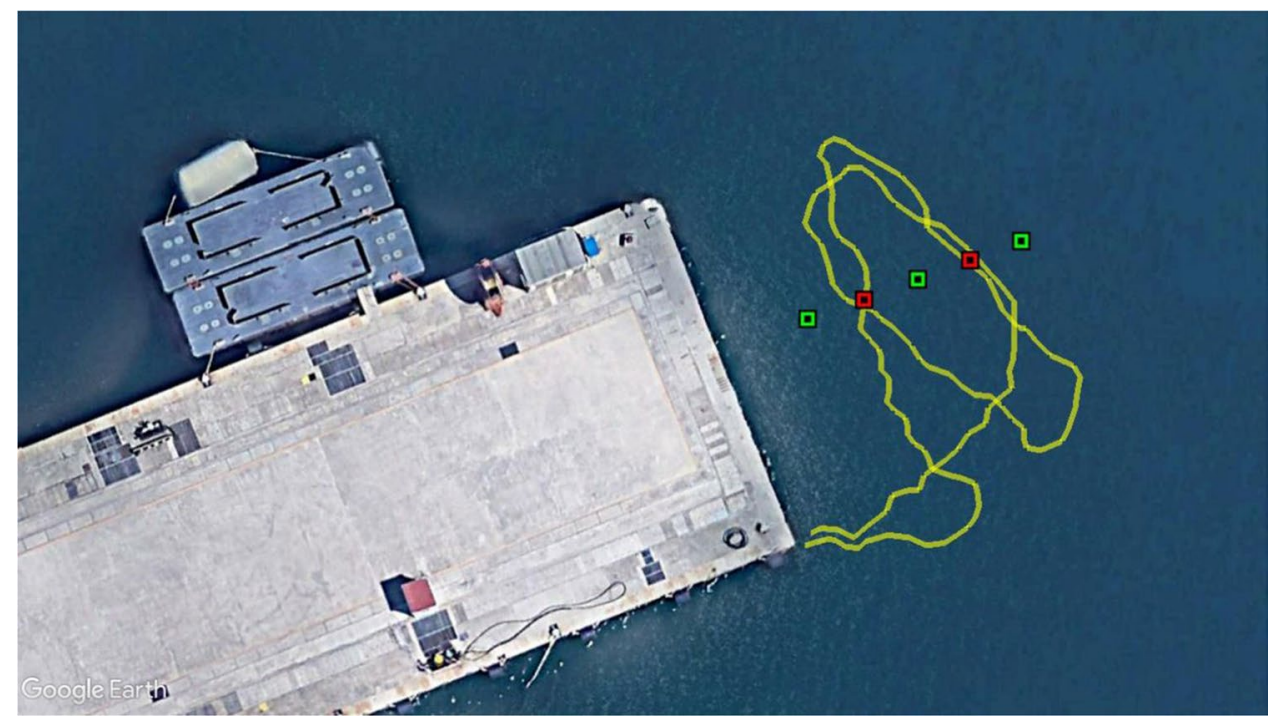

environmental background field and detect anomalies generated by the passages of the diver (Telford et al. 1990; Kanasewich 1981; Faggioni 2018; Faggioni 2019).

Figure 18 shows the detail of the window showing alarms generated while a scuba was crossing the barrier swimming first above the sensors no. 1 and then halfway between no. 2 and 3.

In case of multisensorial harbor protection (appropriately integrated systems so that the shadow areas of each one are filled by others), each alarm must be sent to a control station, which collects the alarms received by all the systems employed (e.g., magnetic, acoustic, optical, infrared, electrical, radar).

The geographic coordinates where each sensor was placed are well known, so each alarm is georeferenced and can be indicated by a red point on a common picture representing the map of the port, as shown in Fig. 19. The yellow line represents the differential GNSS/GPS track of the diver, the red points are the positions of the sensors sending alarm, while the green points indicate sensors not alarmed; to record its position, the scuba was swimming towing a small buoy with a GNSS/GPS logger; after this, his track was downloaded in post-processing phase.

\section{Conclusions}

This paper describes two prototypes of monitoring and processing systems that are being developed with the aim of being useful tools for local authorities to manage port safety and security. Here, the results of their use in Livorno and La Spezia harbors are shown (Italy).

Firstly, the paper highlights the importance of analysis of hydro-barometric inversion for harbor safety. Its applications for harbor waterside management allow us, for example, to improve the effectiveness in maritime works, to help port authorities and pilots decide which the ideal route to follow is for a certain ship, and to optimize ship navigation, dock performance, boats mooring, and refloating of stranded ships.

Then, it is shown how experimental tests carried out on the magnetic detection system, in undersea environments with high magnetic noise, have provided extremely positive operational results in detecting intruders transiting in its proximity, in the case of divers equipped both with steel and aluminum tanks. In the context of antiterrorism systems for harbor protection, the magnetic detection system is required to support the acoustic component in peripheral acoustic shadow zones close to the seabed, docks, piers, and so on.

In a hypothetical operational scenario, both systems could be integrated in a control room managed by a local authority, to provide useful support to make the best decisions in order to ensure safety and security for the community. A common picture representing the map of the port could show both the hypothetical routes that an incoming/outgoing vessel should follow based on its draft ("virtual traffic light"), and any alarms generated by the passage of an intruder detected by the magnetic system (or by acoustic, optical, infrared, electrical, radar, systems in case of multisensorial harbor protection).

Furthermore, for the near future, the goal is to upgrade the magnetic array (now linear) into a two-dimensional system capable not only of detecting a diver entering in a restricted area but also of tracking the threat across the harbor.

Acknowledgements The author wishes to thank Italian National Institute for Environmental Protection and Research (ISPRA) and Port Authority of Livorno for providing meteo-mareographic and bathymetric data, respectively, in particular in Livorno harbor. The author also thanks Dr. O. Faggioni for its cooperation in these studies; Wass SpA (now Leonardo SpA) and SkyTech Srl for their collaboration in the 
development of the magnetic system; Dr. D.A. Leoncini for his contribution in software applications development; Italian Navy for concession of areas, men, and naval vehicles to perform several sea trials.

Part of these activities was conducted when the author was at OGS - National Institute of Oceanography and Applied Geophysics (Trieste, Italy).

The author also thanks the anonymous reviewer, whose comments and suggestions helped improve this work.

Funding Open access funding provided by Istituto Nazionale di Geofisica e Vulcanologia within the CRUI-CARE Agreement. These studies were conducted in collaboration with the Italian Ministry of Defence, European Defence Agency (for harbor protection), and several Italian Port Authorities (for port navigation safety), in particular Port Authority of Livorno; these activities were possible thanks to their funding.

\section{Declarations}

Conflict of interest The author declares no competing interests.

Open Access This article is licensed under a Creative Commons Attribution 4.0 International License, which permits use, sharing, adaptation, distribution and reproduction in any medium or format, as long as you give appropriate credit to the original author(s) and the source, provide a link to the Creative Commons licence, and indicate if changes were made. The images or other third party material in this article are included in the article's Creative Commons licence, unless indicated otherwise in a credit line to the material. If material is not included in the article's Creative Commons licence and your intended use is not permitted by statutory regulation or exceeds the permitted use, you will need to obtain permission directly from the copyright holder. To view a copy of this licence, visit http://creativecommons.org/licenses/by/4.0/.

\section{References}

Allen JS, Denbo DW (1984) Statistical characteristics of the largescale response of coastal sea level to atmospheric forcing. J Phys Oceanogr 14(6):1079-1094

Bartels J, Heck NH, Johnston HF (1992) The three-hour-range index measuring geomagnetic activity. Terr Magn Atmos Electr 44(4):411-454

Cafarella L, De Santis A, Meloni A (1992) A Secular variation in Italy from historical geomagnetic field measurements. Phys Earth Planet Inter 73:206-221

Chapman S (1918) The diurnal changes of the Earth's magnetism. Observatory 41:52-60

Crépon M (1965) Influence de la pression atmospherique sur le niveau moyen de la Méditerranée Occidentale et sur le flux à travers le détroit de Gibraltar. Cah Oceanogr 1:15-32

Dobslaw H, Thomas M (2005) Atmospheric induced oceanic tides from ECMWF forecasts. Geophys Res Lett 32(10):L10615

el-Gindy AAH, Eid FM (1990) Long-term variations of monthly mean sea level and its relation to atmospheric pressure in the Mediterranean Sea. Int Hydrogr Rev 67(1):147-159

Faggioni O (2018) The Fourier notation of the geomagnetic signals informative parameters. J Signal Inform Process 9:153-166

Faggioni $O$ (2019) The information protection in automatic reconstruction of not continuous geophysical data series. J Data Analy Inform Process 7:208-227
Faggioni O (2020) Measurement and forecasting of port tide hydrostatic component in North Tyrrhenian Sea (Italy). Open J Mar Sci 10(2):52-77

Faggioni O, Arena G, Bencivenga M, Bianco G, Bozzano R, Canepa G, Lusiani P, Nardone G, Piangiamore GL, Soldani M, Surace L, Venzano G (2006) The Newtonian approach in meteorological tide waves forecasting: preliminary observations in the East Ligurian harbours. Ann Geophys 49(6):1177-1187

Faggioni O, Soldani M, Leoncini D, Gabellone A, Maggiani PV (2009) Time domain performances analysis of underwater magnetic SIMAN Systems for port protection. J Inf Assur Secur:538-545

Faggioni O, Soldani M, Gabellone A, Hollett RD, Kessel RT (2010) Undersea harbour defence: a new choice in magnetic networks. J Inf Assur Secur 72(1):46-56

Faggioni O, Soldani M, Leoncini DA (2013) Metrological analysis of geopotential gravity field for harbor waterside management and water quality control. Int J Geophys 2013-Special Issue on Geophysical Methods for EnvironmentalStudies, 12 pp

Faggioni O, Soldani M, Cozzani G, Zunino R (2018) Informative signal analysis: metrology of the underwater geomagnetic singularities in low-density ionic solution (sea water). J Signal Inform Process 9:1-23

Garrett C, Toulany B (1982) Sea level variability due to meteorological forcing in the northeast Gulf of St. Lawrence. J Geophys Res 87(C3): $1968-1978$

Garrett C, Majaess F (1984) Nonisostatic response of sea level to atmospheric pressure in the Eastern Mediterranean. J Phys Oceanogr 14(4):656-665

Georgieva K, Kirov B, Nagovitsyn YA (2013) Long-term variations of solar magnetic fields derived from geomagnetic data. Geomagn Aeron 53(7):852-856

Halliwell GR, Allen JS (1984) Large-scale sea level response to atmospheric forcing along the West Coast of North America, Summer 1973. J Phys Oceanogr 14(5):864-886

Kanasewich ER (1981) Time sequence analysis in geophysics. University of Alberta, Edmonton

Le Traon P-Y, Gauzelin P (1997) Response of the Mediterranean mean sea level to atmospheric pressure forcing. J Geophys Res 102(C1):973-984

Leoncini D, Decherchi S, Faggioni O, Gastaldo P, Soldani M, Zunino R (2010) Linear SVM for underwater magnetic signals based port protection. Journal of Information Assurance and Security 5(4):401-408

Meloni A, Cafarella L, De Michelis P, De Santis A, Di Mauro D, Dominici G, Lepidi S, Palangio P, Tozzi R, Zirizzotti (2007) A systematic magnetic observations in Italy. Publicat Instit Geophys -Pol Acad Sci C-99(398):8 pp

Merriam JB (1992) Atmospheric pressure and gravity. Geophys J Int 109(3):488-500

Ponte RM, Gaspar P (1999) Regional analysis of the inverted barometer effect over the global ocean using TOPEX/POSEIDON data and model results. J Geophys Res 104(C7):15587-15601

Telford WM, Geldart P, Sheriff RE (1990) Applied geophysics, 2nd edn. Cambridge University Press, Cambridge

Tsimplis MN (1995) The response of sea level to atmospheric forcing in the Mediterranean. J Coastal Res 11(4):1309-1321

Tsimplis MN, Vlahakis GN (1994) Meteorological forcing and sea level variability in the Aegean Sea. J Geophys Res 99(C5):9879-9890

Wunsch C, Stammer D (1997) Atmospheric loading and the oceanic “inverted barometer" effect. Rev Geophys 35(1):79-107 